\title{
The Rise of Pathogens: Predation as a Factor Driving the Evolution of Human Pathogens in the Environment
}

\author{
Martina Erken • Carla Lutz • Diane McDougald
}

Received: 7 October 2012 / Accepted: 14 January 2013 / Published online: 27 January 2013

(C) The Author(s) 2013. This article is published with open access at Springerlink.com

\begin{abstract}
Bacteria in the environment must survive predation from bacteriophage, heterotrophic protists, and predatory bacteria. This selective pressure has resulted in the evolution of a variety of defense mechanisms, which can also function as virulence factors. Here we discuss the potential dual function of some of the mechanisms, which protect against heterotrophic protists, and how predation pressure leads to the evolution of pathogenicity. This is in accordance with the coincidental evolution hypothesis, which suggests that virulence factors arose as a response to other selective pressures, for example, predation rather than for virulence per se. In this review we discuss some of those environmental factors that may be associated with the rise of pathogens in the marine environment. In particular, we will discuss the role of heterotrophic protists in the evolution of virulence factors in marine bacteria. Finally, we will discuss the implications for expansion of current pathogens and emergence of new pathogens.
\end{abstract}

\section{Introduction}

The rapidly changing environment is increasingly recognized to have an important role in the emergence of pathogens. In the marine environment, these changes will include increases in seawater temperature, changes of currents, increasing eutrophication, and decreases in salinity [1]. An extensive study spanning 50 years of surface seawater

\footnotetext{
M. Erken $\cdot$ C. Lutz $\cdot$ D. McDougald

Centre for Marine Bio-Innovation, School of Biotechnology and Biomolecular Science, University of New South Wales, Sydney, New South Wales 2052, Australia

D. McDougald $(\square)$

Advanced Environmental Biotechnology Centre, Nanyang Environment and Water Research Institute, School of Biological Sciences, Nanyang Technological University, Nanyang Avenue, Singapore 637551, Singapore

e-mail: d.mcdougald@unsw.edu.au
}

samples from the North Sea indicate that increasing seawater temperatures favors the spread of Vibrio spp. [2], including those pathogenic to humans $[3,4]$. It is also becoming clear that infection of humans in many cases is incidental, as virulence factors may have important roles in interactions with predators and non-human hosts in the environment, including bacteriophages, predatory bacteria such as Bdellovibrio, protozoans, nematodes, insects, and plants [5]. Thus, the implications are that many of these virulence factors evolve outside of the context of human disease [6]. In the cases presented here, the selection pressure driving the evolution of these virulence factors was likely to be the predation by heterotrophic protists, and thus predation may explain, at least in part, the evolution of pathogens in the marine environment.

\section{Predation as a Driving Force of Evolution}

Bacteria and heterotrophic protists have a long history of coevolution. Predation by heterotrophic protists is considered to be a major mortality factor in the marine environment [7-10] and is therefore a strong driving force for the evolution of defense strategies [11]. These traits that provide grazing defense may also have resulted in enhanced fitness and pathogenicity of these strains in human (or animal/plant) hosts $[12,13]$. For example, bacteria can avoid being ingested by altering cell surface components, changing cell morphology (e.g. filamentation), increasing swimming speed, biofilm formation, and quorum sensing-regulated toxin release (for reviews see $[11,14,15]$ ). Many of these traits may have led to acquired pathogenicity, suggesting that humans are an accidental rather than intended host [12, 16-18]. In contrast, it can be envisioned that predation in the environment could also lead to a decrease in pathogenicity if the traits that are used for anti-predator defense and human infection are different. In this case the cost of predator defenses may have a fitness trade-off resulting in a decrease 
in pathogenicity traits. Indeed, this may in part explain why most of the bacterial strains found in these environments are in fact not pathogens. Thus, we could envision that only a subset of anti-predator defenses would be effective in the human host and, therefore, only strains exhibiting these defenses would be able to colonize human hosts and hence be pathogenic.

The main question then is whether virulence is a result of natural selection for phenotypes such as avoidance of host immune defenses and infectious transmission or whether virulence factors have roles that increase the fitness of the bacteria in another environment or context. The traditional view of host/pathogen co-evolution is that this association would ultimately end in extinction of one or both partner(s), or in pathogen attenuation and ultimately commensalism $[19,20]$. Thus, virulence is evidence that the association of the bacterium with the host is recent [21]. However, an alternative view is that virulence could be coincidental, i.e., the expression of virulence determinants gives the bacterium an advantage in an out-of-host context. Levin and Eden [22] suggest in their review on host/pathogen coevolution that direct selection would result in attenuation of virulence while coincidental selection would result in maintenance of virulence. The authors suggest that the polysaccharide capsule of Streptococcus pneumoniae is under direct selection as encapsulated strains are selected for in the host and the uncapsulated strains are avirulent. Conversely, it is likely that the Escherichia coli pap adhesin that is responsible for urinary tract infection is under coincidental selection as these adhesins cause an inflammatory response in the urinary tract resulting in clearance, and adhering strains have a disadvantage when competing with nonadhering bacteria for colonization of the urinary tract. It can also be envisioned that both direct and coincidental selection occur simultaneously but act on different virulence determinants. For example, the toxin produced by Vibrio cholerae that is responsible for the explosive diarrhea in cholera patients is probably under direct selection. A role for the toxin in the environment has not been identified and indeed most $V$. cholerae isolates from the environment are non-toxigenic [23]. Furthermore, the expression of this toxin in the human host is important for the dissemination of the bacterium. In contrast, the toxin-coregulated type IV pilus of $V$. cholerae could be under coincidental selection as this pilus is needed for attachment to the chitinous exoskeleton of copepods which is the preferred niche in the environment [24].

Due to the long history of co-evolution of bacteria and protists, many grazing defense strategies have evolved in different bacterial lineages (Table 1). Some bacteria have the ability to resist digestion after phagocytosis and multiply within the amoeba host without killing it (e.g., V. cholerae $[25,26]$ ), while others cause host death (e.g., Legionella pneumophila [27-29]), traits which may contribute to pathogenicity in a human host. In some cases the bacterium can prevent the fusion of the lysosome and phagosome, thereby avoiding digestion [30,31], while others escape lysosomal digestion by entering the cytoplasm of the predator [26].

In some cases, the genes and/or effector proteins regulating the survival of bacteria in the presence of bacterivorous protists have been identified and often these genes/proteins have a defined role in the pathogenicity of these bacterial pathogens towards the human host. In this review we outline a few of these "virulence factors" and discuss their roles both in the environment and in the human host and present evidence that these factors likely evolved to improve bacterial fitness in the environment rather than for pathogenicity per se.

\section{Amoeba as a Selective Force Driving the Evolution of Intracellular Pathogens}

Free-living amoeba such as Dictyostelium discoideum and Acanthamoeba castellanii are useful predator models for the study of how pathogenic bacteria prevent/survive phagocytosis. Both organisms have been extensively studied and share similar characteristics to human macrophages, i.e., both are eukaryotic single cells and phagocytize bacteria. $D$. discoideum shares a range of proteins and metabolic processes with metazoans [32]. In plaque assays Adiba and colleagues demonstrated that $E$. coli strains possessing virulence genes (iron uptake and resistance to serum, bile, and lysozyme/lactoferrin) were resistant to grazing by $D$. discoideum whereas non-virulent strains were eliminated [12]. D. discoideum has been used as a model organism for the identification of virulence factors that are important for survival in co-culture with human pathogens such as Pseudomonas aeruginosa and V. cholerae [33-35].

In some cases co-culture can be advantageous for the prey. In co-culture with $A$. castellanii, Vibrio parahaemolyticus was shown to survive in rich peptone-yeast-glucose (PYG) medium, while no viable bacteria could be detected in PYG alone [36]. V. parahaemolyticus was able to resist phagocytosis by $A$. castellanii; thus, this growth promotion was not due to intracellular survival of $V$. parahaemolyticus but rather was mediated by a factor secreted by $A$. castellanii. Similar results have been presented with $V$. cholerae where the biofilm biomass was increased in the presence of marine heterotrophic nanoflagellates (Cafeteria roenbergensis and Rhynchomonas nasuta) compared to non-grazed controls [37, 38]. Supplementation of $V$. cholerae cultures with supernatants from cultures of predators also resulted in an increase in bacterial biomass. While this may be partly due to recycled nutrients made available by predation, there is evidence that the amount of nutrient provided is not 
Table 1 Examples of factors involved in pathogenicity of a broad range of bacteria are also involved in anti-predation strategies

\begin{tabular}{|c|c|c|c|c|}
\hline System/toxin & Bacterium & Anti-predation & Virulence affecting humans & Reference \\
\hline \multirow[t]{5}{*}{ T3SS } & P. aeruginosa & Kills $A$. castellanii & Pneumonia & {$[86]$} \\
\hline & L. pneumophila & $\begin{array}{l}\text { Parasite inside amoeba and human } \\
\text { monocytes }\end{array}$ & Legionellosis & {$[31,101]$} \\
\hline & E. coli & Survives inside $A$. castellanii & Diarrheal disease & {$[64]$} \\
\hline & Chlamydiae & Endosymbiont of Acanthamoeba sp. & $\begin{array}{l}\text { Trachoma, genital tract infections, and } \\
\text { pneumonia }\end{array}$ & {$[102]$} \\
\hline & V. parahaemolyticus & Toxic towards a range of protist grazers & $\begin{array}{l}\text { Wound infections, septicemia, and acute } \\
\text { gastroenteritis }\end{array}$ & {$[92]$} \\
\hline T6SS & V. cholerae & Cytotoxic against $D$. discoideum & $\begin{array}{l}\text { O1/O139-cholera and non-O1/non-O139 } \\
\text { gastroenteritis }\end{array}$ & {$[34]$} \\
\hline \multirow[t]{3}{*}{ Violacein } & C. violaceum & Causes rapid cell death in protists & Opportunistic pathogen & {$[71,100]$} \\
\hline & J. lividum & Causes rapid cell death in protists & - & - \\
\hline & P. tunicata & Causes rapid cell death in protists & - & - \\
\hline Shiga toxin & E. coli & Stx-carrying bacteria kill T. thermophila & Hemorrhagic colitis & {$[65,66]$} \\
\hline
\end{tabular}

sufficient to fully explain the increase, indicating that a secreted predator cue is involved [39].

\section{Biofilm Formation}

The role of biofilms in human infection and disease has been a topic of intense research over more than 40 years. Biofilms are surface-associated communities of microorganisms encased in extracellular polymeric substances (EPS). Biofilms in the human body are the cause of more than $60 \%$ of infections, including dental plaque and periodontitis [40], infections from biomedical implants such as heart valves (endocarditis) and prosthetic joint implants, catheters and stents, infections in the lungs of cystic fibrosis patients often resulting in bronchopneumonia, persistent otitis media, and chronic rhinosinusitis [41]. Biofilms are especially important in chronic infections as bacterial cells in biofilms are up to 1,000-fold more resistant to antimicrobials than their planktonic counterparts [42]. Understanding the nature of this increased resistance is currently a central goal for medical researchers. Because of their recalcitrance to treatment, biofilm infections typically show recurring symptoms after antibiotic treatment and often, must be removed surgically. A large number of medically important bacteria are able to form biofilms including P. aeruginosa, $E$. coli, Staphylococcus spp., Salmonella typhimurium, L. pneumophila, Haemophilus influenzae, Vibrio spp., and Streptococcus ssp. [43, 44].

Evidence for the occurrence of biofilms in the environment is present in fossil records, for example, in 3.2 billionyear-old deep-sea hydrothermal rocks from Pilbara Craton, Australia [45]. Biofilms are a characteristic of ancient lineages of Archaea and Bacteria, indicating that biofilm formation is an ancient characteristic of microorganisms [43] and implying that biofilms have a role in increasing the fitness of microbes in these environments. Biofilms are common in freshwater environments, often forming a slimy covering on rocks and other submerged surfaces. In the marine environment, biofilms form on all submerged surfaces, including the hulls of ships, buoys and pylons, but the major source of marine biofilms is in aggregates of microorganisms and detritus called marine snow [46].

$V$. cholerae has been observed in the marine environment in biofilms in the form of multicellular aggregated clumps, and it is believed that these biofilms contribute to the persistence of the organism in inter-epidemic periods [47-49]. The formation of biofilms of similar structure has been shown to also occur during human infection [50] and may protect $V$. cholerae from acid $\mathrm{pH}$ and/or antibiotics in the human gut. Furthermore, the biofilms of $V$. cholerae that are shed in human stools have increased infectivity compared to planktonic cells and are thus responsible for high rates of reinfection during outbreaks of cholera [50].

Biofilms formed in the environment have been shown to be more resistant to a variety of stresses, including extremes of temperature, $\mathrm{pH}$, and exposure to UV [43]. There is increasing evidence that biofilms are protective against predation. In biofilms formed by the yeast, Cryptococcus spp., ciliate grazers showed a strong preference for feeding on the EPS rather than on cells embedding in the biofilm, while in the planktonic phase, high numbers of yeast cells were ingested [51]. Furthermore, the number of metabolically active yeast cells in the biofilm was 1.75 times higher in grazed biofilms when compared to non-grazed controls. Thus, EPS from the biofilm may serve as a preferential nutrient source to some predators, and feeding on EPS as opposed to biofilm cells benefits the biofilm not only from protection against ingestion but also due to the increased nutrients provided to the community through nutrient recycling. 
Early biofilms of $V$. cholerae [38] and P. aeruginosa [52] formed grazing-resistant microcolonies in the presence of the surface-feeding flagellate, $R$. nasuta, whereas biofilms without the predator remained undifferentiated. Late, more mature biofilms were toxic to $R$. nasuta, while biofilms formed by a quorum sensing mutant supported the growth of the predator. Thus, microcolony formation and the production of toxins are effective anti-predator mechanisms that allow $V$. cholerae and $P$. aeruginosa to persist in the environment. In addition, while $V$. cholerae biofilms were not grazed, planktonic cells were reduced by $97 \%$ in $72 \mathrm{~h}$ [38]. In the presence of a predator in planktonic populations, there was a shift from the smooth cell morphotype to the biofilm-enhancing rugose morphotype. Further investigations on the relative contribution of EPS to grazing resistance indicated that while EPS provides protection from grazing, the secretion of an anti-protozoal factor is more important in grazing resistance of late biofilms [39]. In $P$. aeruginosa, it was shown that mature biofilms are resistant to a range of biofilm-feeding predators due to the production of an inhibitor, while microcolony formation was only beneficial in the early stages of biofilm formation [53]. Thus, there are multiple anti-predator mechanisms that are expressed at different stages of the life-cycle of these bacteria.

Evidence that the expression of biofilm-mediated predator defense is a general feature of marine biofilm-forming bacteria has been presented in a study comparing the presence and efficacy of chemical defenses in biofilms and planktonic phases of growth. The bacterial isolates used in the study were obtained from the surface of the marine alga, Ulva lactuca, and included representatives of the five main bacterial groups, Bacteriodetes, Planctomycetes, $\alpha-, \delta$-, and $\gamma$-Proteobacteria [54]. When grown planktonically, $90 \%$ of the isolates were edible, resulting in increased predator numbers (180-fold increase on average). In contrast, when the same strains were grown as biofilms, $57 \%$ of the strains caused a significant reduction in predator numbers, indicating that the majority of the strains were grazing resistant only when grown as a biofilm. In semi-natural biofilms formed by microbial populations from the Rhine River, Cologne, Germany, it was shown that the presence of heterotrophic nanoflagellates resulted in an increase in the numbers of microcolonies [55]. Thus, the anti-predator fitness of biofilms is likely to be a conserved grazing resistance mechanism that has evolved because of intense predation pressure in these environments.

\section{Role of Intercellular Communication in Predation Defense and Pathogenicity}

Bacteria communicate through the secretion and perception of chemical cues called autoinducers (AI), in a process termed quorum sensing (QS). AIs accumulate in the environment and when they reach a critical concentration, they bind to and activate intracellular receptors that alter gene expression. QS was first described in Vibrio fischeri where it controls luminescence [56]. For many years, it was thought that QS only occurred in a few marine bacteria, but it is now known to occur in many bacteria. In a large number of these, QS is known to regulate virulence (e.g., Staphylococcus aureus, P. aeruginosa, E. coli, Yersinia spp., Aeromonas spp., and Vibrio spp.) [57]. In order to establish an infection, a pathogen must reach a sufficient density so that it can overcome the host defenses before it expresses virulence factors, otherwise the pathogen will be eliminated by the host immune system. Thus, controlling the expression of virulence factors in a cell-density dependent manner gives the pathogen an advantage. The fact that many virulence factors, such as the production and secretion of toxins, proteases, and siderophores, and the expression of pili are QS-regulated has led to the exploration of QS inhibition as a way to treat bacterial infections [58].

Quorum sensing allows a coordinated, synchronized response by the population to the changing environmental conditions, thereby increasing the fitness of these populations and contributing to their persistence in the environment. Evidence for the role of QS in the regulation of antipredator defenses has been reported for P. aeruginosa [52], $V$. cholerae [38], Chromobacterium violaceum [59], and Serratia marcescens [60] where it was shown that QS mutants have a significantly reduced anti-predator fitness compared to isogenic wild-type strains. In V. cholerae [38] and $P$. aeruginosa [52,61], QS regulates the expression of an unknown toxin that is effective against a range of predators. In the case of $S$. marcescens, the QS-regulation of a filamentous biofilm protected the bacterium from grazing [60]. Indeed, the regulation of biofilm formation and maturation is an important phenotype for environmental persistence.

\section{Shiga Toxin}

Phage-encoded exotoxins, such as cholera toxin, diphtheria toxin, and Shiga toxin (Stx), produced by bacterial isolates kill eukaryotic cells by targeting pathways that are generally conserved. The genes encoding the Shiga exotoxins, stx 1 and $s t \times 2$, are carried on a bacteriophage that infects E. coli. Shiga toxin-carrying E. coli (STEC) can cause severe dysentery-like diarrhea and hemolytic uremic syndrome [62]. Often, these exotoxins are found in environments where there are no mammalian hosts, indicating that these exotoxins may have a role in predation resistance [63].

Stx-producing E. coli $\mathrm{O} 157: \mathrm{H} 7$ are able to survive inside the food vacuoles of Tetrahymena pyriformis [64]. Stxbearing $E$. coli was also shown to have a growth advantage 
over Stx-negative strains in co-culture with the ciliate Tetrahymena thermophila [65], but not when cultured in the absence of the protozoa [64]. When co-cultured with the Stx strain or when pure Shiga toxin was added, the ciliate was killed [65]. The authors suggest that the $\mathrm{H}_{2} \mathrm{O}_{2}$ released by $T$. thermophila induced production of Stx, thereby preventing predation. In this case the release of a toxin that affects humans was directly controlled by the presence of phagotrophic protists.

Although the principle reservoir of STEC is bovines, reports of isolation of stx-carrying E. coli $[66,67]$ and stxencoding phage [63] from the marine coastal environment are increasing. The first report of STEC isolated from marine shellfish originated from the French coastal environment [67]. In a survey by Gourmelon and colleagues [67] covering areas in the English Channel, the Atlantic coast, and Mediterranean Sea, $27.8 \%$ of the samples from oysters, mussels, and cockles were stx positive. Due to the methods used in this survey, it was not possible to differentiate between STEC and stx-encoding prophage, but the results indicate the potential for infection from ingestion of shellfish from this region. Increased runoff from urban and agricultural areas is probably the cause for the increase in abundance of STEC in the marine environment. The authors suggest that although $s t x 2$, which is associated with high human virulence, was not detected in any of the samples, the marine environment acts as a reservoir from which new pathogenic STEC strains can arise. In a more recent study off the coast of Morocco, E. coli O157:H7 and other nonO157 STEC were found with stxl-positive samples comprising $2.1 \%$ of the total shellfish and sediments samples tested. Only shellfish were positive $(0.48 \%)$ for stx2 [66].

In San Diego, California, stx-carrying phages were isolated from terrestrial and aquatic environments where no disease had been reported to date [63]. Exotoxin-specific PCR assays showed that $25 \%$ of all samples analyzed were positive for stx and $18 \%$ of the water samples (combined marine and freshwater samples) were positive. The authors speculate that these phages may play a role in the evolution of human pathogens due to the ease of virulence transfer to non-pathogenic strains.

\section{Violacein}

In 1942 Singh reported that a pigmented extract of $C$. violaceum (along with two other bacteria) prevented ingestion of otherwise edible bacteria by soil amoeba [68]. This purple pigment has been identified as the indole alkaloid, violacein $[69,70]$. Violacein was since found to have antimicrobial, antifungal, antiprotist, antiviral, and even antirotifer properties $[71,72]$. In particular, the anti-protozoan properties of violacein are well documented. In addition to
C. violaceum, many other bacteria produce violacein, including the freshwater bacterium Janthinobacterium lividum and the marine bacteria Alteromonas luteoviolacea [71], Pseudoalteromonas tunicata, Pseudoalteromonas ulvae, Pseudoalteromonas luteoviolacea, and Microbulbifer sp. [73]. The anti-protozoan activity of P. tunicata was determined by bioassay-guided fractionation to be due to violacein as well as the violacein derivative deoxyviolacein. The concentration of violacein in biofilms of different violacein-producing strains was 3 (P. ulvae) to 59 (Microbulbifer sp.) times higher than in planktonically grown bacteria.

In grazing bioassays Matz and colleagues [59] demonstrated that as little as three violacein-producing bacteria ingested by heterotrophic flagellates resulted in rapid cell death after $20 \mathrm{~min}$ and cell lysis within 1 to $2 \mathrm{~h}$. By using a QS mutant strain, they were able to show that toxin production was QS dependent. In experiments with predators exposed to a mixed population of non-toxic and violaceinproducing bacteria, flagellate numbers were inhibited, suggesting an important role for violacein in microbial community dynamics. Violacein also displayed activity against a variety of bacterivorous freshwater zooplankton protists and metazoans. For all zooplankton taxa tested, the presence of $9 \mathrm{ngmL}^{-1}$ violacein, equivalent to the amount present in a mixed population of $10 \%$ C. violaceum, resulted in reduced growth rates by $18-100 \%$ [69].

Although C. violaceum is not a major pathogen, cases of infections have been increasingly reported. In particular, immune-compromised persons and children are vulnerable to C. violaceum infections (e.g. [74-76]). There have also been reports that infections in other mammals have increased [77, 78]. Minor skin trauma appears to be the entrance point for the bacterium into the body, leading to septicemia and liver abscesses, which are often fatal [76]. Violacein induces apoptosis of immune cells such as leukocytes and thus could be important for evasion of the immune system during human infection [79]. As the range of growth temperature of $C$. violaceum is $20-37^{\circ} \mathrm{C}$, rising sea surface temperatures may also increase the prevalence of violaceinproducing bacteria.

\section{Type III Secretion System}

The type III secretion system (T3SS) consists of more than 20 proteins and delivers bacterial effector proteins into eukaryotic host cells. T3SSs can be found in many Gramnegative bacteria [80-82], as well as in an endosymbiont of Acanthamoeba, Protochlamydia amoebophila. Examination of the endosymbiont genome shows little evidence of horizontal gene transfer (HGT) after its divergence from Chlamydiae approximately 700 million years ago [83]. The fact 
that T3SS evolved in this organism long before the appearance of Mammalia 210 million years ago indicates that the T3SS evolved for a purpose other than virulence as such, thus supporting the "coincidental evolution" hypothesis [84].

The T3SS is essential for the survival of pathogenic $E$. coli inside trophozoites of $A$. castellanii [85] and as a QSindependent anti-predator mechanism in P. aeruginosa [86]. The upregulation of T3SS and down-regulation of factors contributing to biofilm formation $[86,87]$ result in a highly motile phenotype, allowing $P$. aeruginosa to rapidly colonize and kill amoeba cells. In the human host, effectors secreted by the $P$. aeruginosa T3SS have profound effects on the progression of pneumonia, further supporting the hypothesis that the evolution of anti-predator defenses might have increased the success of $P$. aeruginosa as a human pathogen.

$V$. parahaemolyticus has emerged as the number one cause of seafood-related bacterial illnesses in many countries [88, 89]. The thermostable direct hemolysin (TDH) is an important virulence factor of $V$. parahaemolyticus, and the T3SS is only present in TDH-positive pathogenic strains [90]. V. parahaemolyticus has two T3SSs; T3SS-1 is encoded on chromosome 1 and is responsible for cytotoxicity, while T3SS-2 carries $2 t d h$ genes and is encoded on chromosome 2 on a virulence pathogenicity island (VPaI-7) acquired by HGT [90, 91]. Matz and colleagues [92] demonstrated that the T3SS-2 was necessary for resistance to grazing by the flagellate $C$. roenbergensis as the biomass of a T3SS-2 mutant was reduced by $80 \%$ while the wild-type strain reduced the flagellate numbers by $85 \%$. In microcosm experiments containing a native coastal plankton community, both $\mathrm{T} 3 \mathrm{SS}-2$ positive and negative strains decreased by about $10 \%$ over a five-day-period. In the presence of heterotrophic and photoautotrophic protists, the T3SS-2-negative $V$. parahaemolyticus population declined 100-fold while in T3SS-2-positive microcosms, a stable $V$. parahaemolyticus population was established and increased by $20 \%$ as the numbers of protists decreased by $59 \%$ [92]. Furthermore, with an increase in the temperature from 16 to $30{ }^{\circ} \mathrm{C}$, the maximum cell density of the T3SS-2positive strain increased while the T3SS-2-negative strain remained suppressed by the ciliate grazer. These data show that the T3SS plays a role in increasing the fitness of $V$. parahaemolyticus in the environment by facilitating invasion of a coastal plankton community and that these strains have an added advantage at higher temperatures which is important in the context of global warming.

\section{Type VI Secretion System}

The type VI secretion system (T6SS), first identified by Spaink and co-workers [6], is found in more than 100 sequenced bacterial genomes, a large number of which are Gram-negative bacterial pathogens (e.g., P. aeruginosa, Salmonella enterica, and Aeromonas hydrophila) and many possessing multiple copies [93]. The T6SS has been demonstrated to be involved in pathogenesis in a number of human pathogens [94-96]. This secretion system was demonstrated to be required for cytotoxicity of $V$. cholerae towards Dictyostelium and mammalian macrophages by a contact-dependent mechanism [34]. In A. hydrophila the expression of T3SS and T6SS, as well as QS and lateral flagella, is positively linked. In fact, the link between regulation of T3SS and T6SSs has been reported for a number of bacteria [97]. However, the majority of bacteria possessing T6SSs are not pathogens, but rather occur in marine and soil environments and there is strong evidence that in many of these cases, the T6SS has a role in interactions with other bacteria [98]. Thus, it is likely that T6SSs have a broad role for increasing bacterial fitness in the environment rather than in pathogen/host interactions per se. Supporting this is the fact that T6SS, T3SS, flagellar synthesis, biofilm formation, and quorum sensing are linked in many bacteria and these systems are all known to play roles in environmental fitness. In the case of $V$. cholerae, while there is clear evidence that genes encoded in the T6SS are important for survival in Dictyostelium and the deletion of the effector protein, Hcp, had no effect in a mouse model of infection, highlighting that its role in virulence in the human is unclear [34, 99].

\section{Conclusions}

Amoeba and macrophages have similar mechanisms of phagocytosis and prey inactivation [100] and therefore, the resistance mechanisms that are important for survival of both ingestion by amoeba and phagocytosis by immune cells seem to be similar, supporting the idea that resistance to amoeba is an important driving force in the evolution of intracellular pathogens [11, 27]. Likewise, pre-ingestional protective mechanisms may also be similar to those needed by pathogenic bacteria to evade eukaryotic immune systems. For example, biofilm production and QS-mediated secretion of virulence factors by $P$. aeruginosa and $V$. cholerae are important for both environmental survival and resistance to predation by heterotrophic nanoflagellates [38, 52, 53, 86, 92]. Thus, the similarities between antipredator defense mechanisms and defenses against phagocytes suggest a causal link in pathogenicity and environmental persistence. This has profound implications for the evolution of virulent strains in the environment, as many virulence factors that are studied in the context of human disease potentially have functions in natural microbial communities. A better understanding of these roles would allow 
us to predict how such pathogens arise and persist in the environment. Therefore, future research should be directed at the better understanding of the role of predation in microbial community function, diversity, and stability.

Acknowledgments Work in the authors' laboratory is supported by the Centre for Marine Bio-Innovation, University of New South Wales and grants from the Australian Research Council. We would like to thank the three reviewers for their helpful comments.

Open Access This article is distributed under the terms of the Creative Commons Attribution License which permits any use, distribution, and reproduction in any medium, provided the original author(s) and the source are credited.

\section{References}

1. Harvell CD, Mitchell CE, Ward JR, Altizer S, Dobson AP, Ostfeld RS, Samuel MD (2002) Climate warming and disease risks for terrestrial and marine biota. Science 296:2158-2162

2. Vezzulli L, Brettar I, Pezzati E, Reid PC, Colwell RR, Höfle MG, Pruzzo C (2012) Long-term effects of ocean warming on the prokaryotic community: evidence from the vibrios. ISME J 6:21-30

3. Baker-Austin C, Trinanes JA, Taylor NG, Hartnell R, Siitonen A, Martinez-Urtaza J (2013) Emerging Vibrio risk at high latitudes in response to ocean warming. Nat Climate Change Adv Online Publ 3:73-77. doi:10.1038/nclimate1628

4. Oberbeckmann S, Wichels A, Wiltshire K, Gerdts G (2011) Occurrence of Vibrio parahaemolyticus and Vibrio alginolyticus in the German Bight over a seasonal cycle. Antonie Leeuwenhoek 100:291-307

5. Pallen M, Wren B (2007) Bacterial pathogenomics. Nature 449:835-842

6. Bladergroen MR, Badelt K, Spaink HP (2003) Infection-blocking genes of a symbiotic Rhizobium leguminosarum strain that are involved in temperature-dependent protein secretion. Mol Plant Microbe Int 16:53-64

7. Fenchel T (1987) Ecology of protozoa: the biology of free-living phagotrophic protists. Science Tech, Madison

8. Hahn MW, Höfle MG (2001) Grazing of protozoa and its effect on populations of aquatic bacteria. FEMS Microbiol Ecol 35:113

9. Sherr E, Sherr B (2002) Significance of predation by protists in aquatic microbial food webs. Antonie Leeuwenhoek 81:293-308

10. Sherr EB, Sherr BF (1994) Bacterivory and herbivory: key roles of phagotrophic protists in pelagic food webs. Microb Ecol 28:223-235

11. Matz C, Kjelleberg S (2005) Off the hook-how bacteria survive protozoan grazing. Trends Microbiol 13:302-307

12. Adiba S, Nizak C, van Baalen M, Denamur E, Depaulis F (2010) From grazing resistance to pathogenesis: the coincidental evolution of virulence factors. PLoS One 5:e11882

13. Brown MRW, Barker J (1999) Unexplored reservoirs of pathogenic bacteria: protozoa and biofilms. Trends Microbiol 7:46-50

14. Jürgens K, Matz C (2002) Predation as a shaping force for the phenotypic and genotypic composition of planktonic bacteria. Antonie Leeuwenhoek 81:413

15. Pernthaler J (2005) Predation on prokaryotes in the water column and its ecological implications. Nature Rev Microbiol 3:537

16. Casadevall A, Pirofski L (2007) Accidental virulence, cryptic pathogenesis, Martians, lost hosts, and the pathogenicity of environmental microbes. Eukaryot Cell 6:2169-2174
17. Coombes BK (2009) Type III secretion systems in symbiotic adaptation of pathogenic and non-pathogenic bacteria. Trends Microbiol 17:89-94

18. Goebel W, Gross R (2001) Intracellular survival strategies of mutualistic and parasitic prokaryotes. Trends Microbiol 9:267-273

19. May RM, Anderson RM (1983) Parasite-host coevolution. In: Futuyma DJ, Slatkin M (eds) Coevolution. Sinauer Associates, Sunderland, pp 186-206

20. Brown SP, Cornforth DM, Mideo N (2012) Evolution of virulence in opportunistic pathogens: generalism, plasticity, and control. Trends Microbiol 20:336-342. doi:10.1016/j.tim.2012.04.005

21. Levin BR (1996) The evolution and maintenance of virulence in microparasites. Emerg Infect Dis 2:93-102. doi:papers2:// publication/uuid/631CC101-4C96-48E8-8560-96F08AD4A091

22. Levin BR, Eden CS (1990) Selection and evolution of virulence in bacteria: an ecumenical excursion and modest suggestion. Parasitology 100:S103-S115

23. Chakraborty S, Mukhopadhyay AK, Bhadra RK, Ghosh AN, Mitra R, Shimada T, Yamasaki S, Faruque SM, Takeda Y, Colwell RR, Nair GB (2000) Virulence genes in environmental strains of Vibrio cholerae. Appl Environ Microbiol 66:4022-4028

24. Huq A, Small EB, West PA, Huq MI, Rahman R, Colwell RR (1983) Ecological relationships between Vibrio cholerae and planktonic crustacean copepods. Appl Environ Microbiol 45:275-283

25. Abd H, Saeed A, Weintraub A, Nair GB, Sandstrom G (2007) Vibrio cholerae $\mathrm{O} 1$ strains are facultative intracellular bacteria, able to survive and multiply symbiotically inside the aquatic freeliving amoeba Acanthamoeba castellanii. FEMS Microbiol Ecol 60:33-39

26. Abd H, Weintraub A, Sandstrom G (2005) Intracellular survival and replication of Vibrio cholerae $\mathrm{O} 139$ in aquatic free-living amoebae. Environ Microbiol 7:1003-1008

27. Barker J, Brown MRW (1994) Trojan horses of the microbial world: protozoa and the survival of bacterial pathogens in the environment. Microbiology 140:1253-1259

28. Kirby JE, Vogel JP, Andrews HL, Isberg RR (1998) Evidence for pore-forming ability by Legionella pneumophila. Mol Microbiol 27:323-336

29. Lau H, Ashbolt N (2009) The role of biofilms and protozoa in Legionella pathogenesis: implications for drinking water. J Appl Microbiol 107:368-378

30. Greub G, Raoult D (2004) Microorganisms resistant to free-living amoebae. Clin Microbiol Rev 17:413-433

31. Hägele S, Köhler R, Merkert H, Schleicher M, Hacker J, Steinert M (2001) Dictyostelium discoideum: a new host model system for intracellular pathogens of the genus Legionella. Cell Microbiol $2: 165-171$

32. Annesley SJ, Fisher PR (2009) Dictyostelium discoideum-a model for many reasons. Mol Cell Biochem 329:73-91

33. Cosson P, Zulianello L, Join-Lambert O, Faurisson F, Gebbie L, Benghezal M, Van Delden C, Curty LK, Kohler T (2002) Pseudomonas aeruginosa virulence analyzed in a Dictyostelium discoideum host system. J Bacteriol 184:3027-3033

34. Pukatzki S, Ma AT, Sturtevant D, Krastins B, Sarracino D, Nelson WC, Heidelberg JF, Mekalanos JJ (2006) Identification of a conserved bacterial protein secretion system in Vibrio cholerae using the Dictyostelium host model system. Proc Natl Acad Sci U S A 103:1528-1533

35. Thom S, Warhurst D, Drasar BS (1992) Association of Vibrio cholerae with fresh water amoebae. J Med Microbiol 36:303-306

36. Laskowski-Arce MA, Orth K (2008) Acanthamoeba castellanii promotes the survival of Vibrio parahaemolyticus. Appl Environ Microbiol 74:7183-7188

37. Erken M, Weitere M, Kjelleberg S, McDougald D (2011) In situ grazing resistance of Vibrio cholerae in the marine environment. FEMS Microbiol Ecol 76:504-512 
38. Matz C, McDougald D, Moreno AM, Yung PY, Yildiz FH, Kjelleberg S (2005) Biofilm formation and phenotypic variation enhance predation-driven persistence of Vibrio cholerae. Proc Natl Acad Sci U S A 102:16819-16824

39. Sun S, Kjellberg S, McDougald D (2012) Relative contributions of Vibrio polysaccharide and quorum sensing to the resistance of Vibrio cholerae to predation by heterotrophic protists. PLoS One (in press)

40. Kolenbrander PE, Palmer RJ, Periasamy S, Jakubovics NS (2010) Oral multispecies biofilm development and the key role of cellcell distance. Nat Rev Microbiol 8:471-480

41. Costerton JW, Stewart PS, Greenberg EP (1999) Bacterial biofilms: a common cause of persistant infections. Science 284:1318-1322

42. Hoiby N, Bjarnsholt T, Givskov M, Sr M, Ciofu O (2010) Antibiotic resistance of bacterial biofilms. Int $\mathrm{J}$ Antimicrob Agents 35:322-332

43. Hall-Stoodley L, Costerton JW, Stoodley P (2004) Bacterial biofilms: from the natural environment to infectious diseases. Nature Rev Microbiol 2:95-108

44. Parsek MR, Singh PK (2003) Bacterial biofilms: an emerging link to disease pathogenesis. Annu Rev Microbiol 57:677-701

45. Rasmussen B (2000) Filamentous microfossils in a 3,235-million year-old volcanogenic massive sulphide deposit. Nature 405:676-679

46. Silver MW, Shanks AL, Trent JD (1978) Marine snow: microplanton habitat and source of small-scale patchiness in pelagic population. Science 201:371-373

47. Alam M, Sultana M, Nair GB, Sack RB, Sack DA, Siddique AK, Ali A, Huq A, Colwell RR (2006) Toxigenic Vibrio cholerae in the aquatic environment of Mathbaria, Bangladesh. Appl Environ Microbiol 72:2849-2855

48. Alam M, Sultana M, Nair GB, Siddique AK, Hasan NA, Sack RB, Sack DA, Ahmed KU, Sadique A, Watanabe H, Grim CJ, Huq A, Colwell RR (2007) Viable but nonculturable Vibrio cholerae $\mathrm{O} 1$ in biofilms in the aquatic environment and their role in cholera transmission. Proc Natl Acad Sci 104:17801-17806

49. Huq A, Whitehouse CA, Grim CJ, Alam M, Colwell RR (2008) Biofilms in water, its role and impact in human disease transmission. Curr Opin Biotechnol 19:244-247

50. Faruque SM, Biswas K, Udden SMN, Ahmad QS, Sack DA, Nair GB, Mekalanos JJ (2006) Transmissibility of cholera: in vivoformed biofilms and their relationship to infectivity and persistence in the environment. Proc Natl Acad Sci U S A 103:6350-6355

51. Joubert LM, Wolfaardt GM, Botha A (2006) Microbial erxopolymers link predator and prey in a model yeast biofilm system. Microb Ecol 52:187-197

52. Matz C, Bergfeld T, Rice SA, Kjelleberg S (2004) Microcolonies, quorum sensing and cytotoxicity determine the survival of Pseudomonas aeruginosa biofilms exposed to protozoan grazing. Environ Microbiol 6:218-226

53. Weitere M, Bergfeld T, Rice SA, Matz C, Kjelleberg S (2005) Grazing resistance of Pseudomonas aeruginosa biofilms depends on type of protective mechanism, developmental stage and protozoan feeding mode. Environ Microbiol 7:1593-1601

54. Longford SR, Crocettei GR, Holmes AJ, Holmstrom C, Kjelleberg S, Steinberg P, Taylor MW (2007) Comparisons of diversity of bacterial communities associated with three sessile marine eukaryotes. Aquat Microb Ecol 48:217-229

55. Wey JK, Scherwass A, Norf H, Arndt H, Weitere M (2008) Effects of protozoan grazing within river biofilms under seminatural conditions. Aquat Microb Ecol 52:283-296

56. Nealson KH (1977) Autoinduction of bacterial luciferase. Occurrence, mechanism and significance. Arch Microbiol 112:73-79

57. Williams P, Camara M, Hardman A, Swift S, Milton D, Hope VJ, Winzer K, Middleton B, Pritchard DI, Bycroft BW (2000)
Quorum sensing and the population-dependent control of virulence. Phil Trans R Soc London 355:667-680

58. McDougald D, Rice SA, Kjelleberg S (2007) Bacterial quorum sensing and interference by naturally occurring biomimics. Anal Bioanal Chem 387:445-453

59. Matz C, Deines P, Boenigk J, Arndt H, Eberl L, Kjelleberg S, Jürgens K (2004) Impact of violacein-producing bacteria on survival and feeding of bacterivorous nanoflagellates. Appl Environ Microbiol 70:1593-1599

60. Queck S-Y, Weitere M, Moreno AM, Rice SA, Kjelleberg S (2006) The role of quorum sensing mediated developmental traits in the resistance of Serratia marcescens biofilms against protozoan grazing. Environ Microbiol 8:1017-1025

61. Pukatzki S, Kessin RH, Mekalanos JJ (2002) The human pathogen Pseudomonas aeruginosa utilizes conserved virulence pathways to infect the social amoeba Dictyostelium discoideum. Proc Natl Acad Sci U S A 99:3159-3164

62. Miyagi K, Omura K, Ogawa A, Hanafusa M, Nakano Y, Morimatsu S, Sano K (2001) Survival of Shiga toxin-producing Escherichia coli $\mathrm{O} 157$ in marine water and frequent detection of the Shiga toxin gene in marine water samples from an estuary port. Epidemiol Infect 126:129-133

63. Casas V, Maloy S (2011) Role of bacteriophage-encoded exotoxins in the evolution of bacterial pathogens. Future Microbiol 6:1461-1473

64. Meltz Steinberg K, Levin BR (2007) Grazing protozoa and the evolution of the Escherichia coli O157:H7 Shiga toxin-encoding prophage. Proc R Soc Lond B 274:1921-1929

65. Lainhart W, Stolfa G, Koudelka GB (2009) Shiga toxin as a bacterial defense against a eukaryotic predator, Tetrahymena thermophila. J Bacteriol 191:5116-5122

66. Bennani M, Badri S, Baibai T, Oubrim N, Hassar M, Cohen N, Amarouch H (2011) First detection of Shiga toxin-producing Escherichia coli in shellfish and coastal environments of Morocco. Appl Biochem Biotechnol 165:290-299

67. Gourmelon M, Montet M, Lozach S, Le Mennec C, Pommepuy M, Beutin L, Vernozy-Rozand C (2006) First isolation of Shiga toxin-producing Escherichia coli variant strains in shellfish from coastal areas in France. J Appl Microbiol 100:85-97

68. Singh B (1942) Toxic effects of certain bacterial metabolic products on soil protozoa. Nature 149:168

69. Deines P, Matz C, Jürgens K (2009) Toxicity of violaceinproducing bacteria fed to bacterivorous freshwater plankton. Limnol Oceanogr 54:1343-1352

70. Lichstein HC, Van De Sand VF (1945) Violacein, an antibiotic pigment produced by Chromobacterium violaceum. J Infect Dis 76:47-51

71. Durán N, Justo GZ, Ferreira CV, Melo PS, Cordi L, Martins D (2007) Violacein: properties and biological activities. Biotechnol Appl Biochem 48:127-133

72. Harris RN, Brucker RM, Walke JB, Becker MH, Schwantes CR, Flaherty DC, Lam BA, Woodhams DC, Briggs CJ, Vredenburg VT, Minbiole KPC (2009) Skin microbes on frogs prevent morbidity and mortality caused by a lethal skin fungus. ISME J 3:818-824

73. Matz C, Webb JS, Schupp PJ, Phang SY, Penesyan A, Egan S, Steinberg P, Kjelleberg S (2008) Marine biofilm bacteria evade eukaryotic predation by targeted chemical defense. PLoS One 3: e2744

74. Baker S, Campbell JI, Stabler R, Nguyen HVM, To DS, Nguyen DV, Farrar J (2008) Fatal wound infection caused by Chromobacterium violaceum in Ho Chi Minh City, Vietnam. J Clin Microbiol 46:3853-3855

75. Lee J, Kim J, Nahm C, Choi J, Kim J, Pai S, Moon K, Lee K, Chong Y (1999) Two cases of Chromobacterium violaceum infection after injury in a subtropical region. J Clin Microbiol 37:2068-2070 
76. Midani S, Rathore M (1998) Chromobacterium violaceum infection. South Med J 91:464

77. Baldi M, Morales JA, Hernández G, Jiménez M, Alfaro A, Barquero-Calvo E (2010) Chromobacterium violaceum infection in a free-ranging Howler monkey in Costa Rica. J Wildl Dis 46:306-310

78. Liu DX, Didier PJ, Plauche GB (2012) Chromobacterium violaceum infections in 13 non-human primates. J Med Primatol 41:107-114

79. Fierreira CV, Bos CL, Versteeg HH, Justo GZ, Durán N, Peppelenbosch MP (2004) Molecular mechanism of violaceinmediated human leukemia cell death. Blood 104:1459-1464

80. Coburn B, Sekirov I, Finlay BB (2007) Type III secretion systems and disease. Clin Microbiol Rev 20:535-549

81. Galan JE, Collmer A (1999) Type III secretion machines: bacterial devices for protein delivery into host cells. Science 284:1322-1328

82. Galán JE, Wolf-Watz H (2006) Protein delivery into eukaryotic cells by type III secretion machines. Nature 444:567-573

83. Horn M, Collingro A, Schmitz-Esser S, Beier CL, Purkhold U, Fartmann B, Brandt P, Nyakatura GJ, Droege M, Frishman D, Rattei T, Mewes H-W, Wagner M (2004) Illuminating the evolutionary history of Chlamydiae. Science 304:728-730

84. Levin B (1996) The evolution and maintenance of virulence in microparasites. Emerg Infect Dis 2:93-102

85. Siddiqui R, Malik H, Sagheer M, Jung S-Y, Khan NA (2011) The type III secretion system is involved in Escherichia coli $\mathrm{K} 1$ interactions with Acanthamoeba. Exp Parasitol 128:409-413

86. Matz C, Moreno A, Alhede M, Manefield M, Hauser A, Givskov M, Kjelleberg S (2008) Pseudomonas aeruginosa uses type III secretion system to kill biofilm-associated amoebae. ISME J $2: 843-852$

87. Kuchma SL, Connolly JP, O'Toole GA (2005) A threecomponent regulatory system regulates biofilm maturation and type III secretion in Pseudomonas aeruginosa. J Bacteriol 187:1441-1454

88. Daniels NA, MacKinnon L, Bishop R, Altekruse S, Ray B, Hammond RM, Thompson S, Wilson S, Bean NH, Griffin PM (2000) Vibrio parahaemolyticus infections in the United States, 1973-1998. J Infect Dis 181:1661-1666

89. Nair GB, Ramamurthy T, Bhattacharya SK, Dutta B, Takeda Y, Sack DA (2007) Global dissemination of Vibrio parahaemolyticus serotype O3: K6 and its serovariants. Clin Microbiol Rev 20:39-48

90. Makino K, Oshima K, Kurokawa K, Yokoyama K, Uda T, Tagomori K, Iijima Y, Najima M, Nakano M, Yamashita A (2003) Genome sequence of Vibrio parahaemolyticus: a pathogenic mechanism distinct from that of $V$. cholerae. Lancet 361:743-749

91. Izutsu K, Kurokawa K, Tashiro K, Kuhara S, Hayashi T, Honda $\mathrm{T}$, Iida $\mathrm{T}$ (2008) Comparative genomic analysis using microarray demonstrates a strong correlation between the presence of the 80kilobase pathogenicity island and pathogenicity in Kanagawa phenomenon-positive Vibrio parahaemolyticus strains. Infect Immun 76:1016-1023

92. Matz C, Nouri B, McCarter L, Martinez-Urtaza J (2011) Acquired type III secretion system determines environmental fitness of epidemic Vibrio parahaemolyticus in the interaction with bacterivorous protists. PLoS One 6:e20275

93. Bingle LEH, Bailey CM, Pallen MJ (2008) Type VI secretion: a beginner's guide. Curr Opin Microbiol 11:3-8

94. Folkesson A, Lofdahl S, Normark S (2002) The Salmonella enterica subspecies I specific centisome 7 genomic island encodes novel protein families present in bacteria living in close contact with eukaryotic cells. Res Microbiol 153:537-545

95. LLoyd AL, Henderson TA, Vigil PD, Mobley HLT (2009) Genomic islands of uropathogenic Eschericia coli contribute to virulence. J Bacteriol 191:3469-3481

96. Dudley EG, Thomson NR, Parkhill J, Morin NP, Nataro JP (2006) Proteomic and microarray characterization of the AggR regulon identifies a pheU pathogenicity island in enteroaggregative Escherichia coli. Mol Microbiol 61:1267-1282. doi:10.1111/ j.1365-2958.2006.05281.x

97. Leung KY, Siame BA, Snowball H, Mok YK (2011) Type VI secretion regulation: crosstalk and intracellular communication. Curr Opin Microbiol 14:9-15

98. Schwarz S, Hood RD, Mougous JD (2010) What is type VI secretion doing in all those bugs? Trends Microbiol 18:531-537

99. Williams SG, Varcoe LT, Attridge SR, Manning PA (1996) Vibrio cholerae Hcp, a secreted protein coregulated with HylA. Infect Immun 64:283-289

100. Davies B, Chattings LS, Edwards SW (1991) Superoxide generation during phagocytosis by Acanthamoeba castellanii: similarities to the respiratory burst of immune phagocytes. J Gen Microbiol 137:705-710

101. Cirillo JD, Cirillo SLG, Yan L, Bermudez LE, Falkow S, Tompkins LS (1999) Intracellular growth in Acanthamoeba castellanii affects monocyte entry mechanisms and enhances virulence of Legionella pneumophila. Infect Immun 67:4427-4434

102. Wagner M, Horn M (2006) The Planctomycetes, Verrucomicrobia, Chlamydiae and sister phyla comprise a superphylum with biotechnological and medical relevance. Curr Opin Biotechnol $17: 241-249$ 